\title{
Monoclonal antibodies to the cells of a regenerating $\operatorname{limb}$
}

\author{
CHRIS R. KINTNER AND JEREMY P. BROCKES
}

Division of Biology, California Institute of Technology, Pasadena, CA 91125, U.S.A. and the MRC Cell Biophysics Unit, Kings College London, 26-29 Drury Lane, London, WC2B 5RL, U.K.

\begin{abstract}
SUMMARY
Monoclonal antibodies were raised against differentiated cells, and blastemal cells from regenerating limbs of adult newts (Notophthalmus viridescens) and screened for specific staining by immunocytochernistry. In addition to antibodies that identify muscle, Schwann cells and cartilage, two reagents were specific for subpopulations of blastemal cells. One of these latter antibodies, termed $22 / 18$, has provided new evidence about the origin of blastemal cells from Schwann cells and myofibres, and also identifies blastemal cells whose division is persistently dependent on the nerve supply.
\end{abstract}

\section{INTRODUCTION}

Amputation of the limb in Urodele amphibians is followed by formation of a blastema, a growth zone composed of undifferentiated cells. The cells of the blastema are unusual in that they appear to originate from differentiated tissue after amputation, a process referred to as dedifferentiation, yet in many respects they are similar to embryonic progenitor cells. They are capable of extensive division during the early period of blastemal growth, apparently in response to a stimulus from the nerve supply, and they subsequently give rise to the various cell types that make up the internal tissue of the regenerate (for a review of limb regeneration see Wallace, 1981).

The classical anatomical descriptions of limb regeneration have emphasized that blastemal cells are indistinguishable by morphological criteria from the time that they arise until the onset of terminal differentiation (Thornton, 1938; Chalkley, 1954; Salpeter \& Singer, 1960; Hay, 1962, among others) although some recent attempts have been made to make such distinctions (Geraudie \& Singer, 1981). Despite this apparent homogeneity, it is possible that blastemal cells comprise a progenitor population of several different cell types and that such heterogeneity is reflected by molecular rather than morphological differences. There are several

Key words: monoclonal antibodies, regeneration, cell markers, Notophthalmus viridescens, blastema, Schwann cells. 
possible sources of heterogeneity within this population including the cell type from which blastemal cells are derived (Chalkley, 1954) and their location with respect to positional cues (French, Bryant \& Bryant, 1976). The identification of such non-equivalent sets would be an important step towards analysing the cellular composition of the blastema.

In many systems, the analysis of cell heterogeneity and its relation to cell function has depended on cell markers. Much of the progress in cellular immunology, for example, reflects the use of antibodies that allow identification and manipulation of different classes of lymphocytes (Mishell \& Shiigi, 1980). In the case of limb regeneration, we have begun by isolating markers that distinguish between blastemal cells and the various differentiated cell types, or ones that distinguish between blastemal cells themselves. These markers have been obtained by generating monoclonal antibodies against differentiated tissue and blastemal tissue from the limbs of adult newts (Notophthalmus viridescens). The antibodies were screened by indirect immunofluorescence of tissue sections of regenerating limbs in order to detect reagents that were cell specific. Several markers for myelin, myofibres, and cartilage were defined. In addition, two antibodies were obtained that distinguish between blastemal cells and reveal a change in the cellular composition of the blastema with time after amputation. One of these reagents, 22/18, has been used in conjunction with markers for differentiated tissue to obtain new evidence about the origin of some blastemal cells from muscle fibres and Schwann cells. Furthermore, 22/18 identifies cells whose division is persistently dependent on the nerve supply, even in the later stage of regeneration.

\section{MATERIALS AND METHODS}

\section{Animals}

Adult newts, Notophthalmus viridescens, from Lee's Newt Farm, Tennessee were maintained in the laboratory at $20-23^{\circ} \mathrm{C}$ and fed dried Tubifex worms twice weekly. Operations were performed on animals anaesthetized with $0.1 \%$ Tricane. Forelimbs were amputated by cutting the limb just below the elbow, pushing the soft tissue down the bone, cutting the bone and then trimming the soft tissue to produce a flat amputation surface. The stage of regeneration was judged according to the classification of Iten \& Bryant (1973).

\section{Tissue preparation for immunization}

Various tissues were dissected from adult newts for use as immunogen and stored at $-80^{\circ} \mathrm{C}$. Muscle was taken from forelimbs, cartilage from epiphyses of forelimb bones, and blastemal tissue from early to midbud-stage forelimb regenerates. Crude homogenates were prepared from muscle and cartilage by homogenizing $1 \mathrm{gm}$ wet-weight tissue in a Dounce homogenizer with 10 strokes in 10 vols phosphate-buffered saline (PBS: $0.15 \mathrm{M}-\mathrm{NaCl}, 0.05 \mathrm{M}$-sodium phosphate, $\mathrm{pH} 7 \cdot 2$ ), followed by centrifugation at $700 \mathrm{~g}$ for $15 \mathrm{~min}$ to remove large debri. A crude membrane pellet was prepared from medium-bud blastemas by homogenizing $0.5 \mathrm{gm}$, wetweight (approx. 200 blastemas) tissue in $0.32 \mathrm{M}$-sucrose, $5 \mathrm{~mm}$-sodium phosphate, $\mathrm{pH} 7.4$ and 1 mM-phenylmethylsulphonyl fluoride (Buffer A), followed by centrifugation of the crude homogenate at $11000 \mathrm{~g}$ for $60 \mathrm{~min}$. The pellet was washed once in buffer $\mathrm{A}$ and resuspended in 
PBS. Myelin was prepared from homogenized peripheral nerves by centrifugation through a discontinuous sucrose gradient as described previously (Fryxell, Balzer \& Brockes, 1983).

An alternative preparation of blastemal tissue for immunization was to prepare a crude membrane fraction from mechanically dissociated blastemal cells. Blastemas were removed from early- to medium-bud regenerates and mechanically dissociated by gently shearing in a loose-fitting glass homogenizer in Hepes-buffered saline (HBS: $120 \mathrm{~mm}-\mathrm{NaCl}, 3 \mathrm{~mm}-\mathrm{KCl}$, $0.01 \mathrm{~mm}-\mathrm{CaCl}_{2}, 5 \mathrm{~mm}-\mathrm{Hepes}, \mathrm{pH} 7 \cdot 2$ ). Dissociated cells were filtered through nylon mesh to remove the undissociated epidermis and sedimented at $400 \mathrm{~g}$ for $10 \mathrm{~min}$ at $20^{\circ} \mathrm{C}$ through a discontinuous gradient consisting of layers of $20 \%, 15 \%, 10 \%$ and $5 \%$ Ficoll in HBS. Cells were collected from the $15 \%$ and $10 \%$ layers and interface, washed once in HBS and stored at $-70^{\circ} \mathrm{C}$. Crude membranes were prepared from dissociated cells as described above for tissue sources.

\section{Immunization}

Balb/c female mice were primed (50-100 micrograms protein/mouse) with an emulsion of Freund's complete adjuvant and either crude homogenates, crude membrane fractions from tissue or crude membrane fractions from dissociated cells. Two weeks later, mice were boosted with the same material emulsified in Freund's incomplete adjuvant. After at least two weeks, mice were boosted by intraperitoneal injections on 4,3 and 2 days before being sacrificed for the production of hybridomas.

\section{Production of monoclonal antibodies}

Hybridomas were generated from spleen cells of immunized mice by polyethylene glycol mediated fusion to a myeloma cell line, NS-1, using essentially the method of Kohler \& Milstein (1975) as described previously (Moore, Fritz, Raftery \& Brockes, 1982). Hybridoma clones were first screened for antibody secretion using a solid-phase, enzyme-linked, immunosorbent assay (Engvall \& Perlmann, 1972). Antibody-secreting clones were tested by indirect immunofluorescence on frozen tissue sections of regenerating limbs as described below. Hybridoma clones that showed noteworthy specificity were cloned several times by limiting dilution and used to produce high titre fluids from ascites tumours.

\section{Immunohistochemistry}

$22 / 31$ and 22/18 antibodies (both IgM) were purified from ascites fluids by exclusion chromatography on AcA 34 (LKB) in PBS, $0.1 \%$ sodium azide. Protein in the void volume was pooled, dialysed against PBS, $0.1 \%$ sodium azide and stored in aliquots at $1.0 \mathrm{mg} \mathrm{m}^{-1}$ at $-70^{\circ} \mathrm{C}$. $22 / 31$ antibody was biotinylated using biotin succinimide ester (BSE, Sigma) by standard techniques. In brief, a $1.0 \mathrm{mg} \mathrm{ml}^{-1}$ solution of BSE in dimethyl sulphoxide was mixed in varying ratios (1:4 to $1: 16$, biotin: protein) with a $1.0 \mathrm{mg} \mathrm{ml}^{-1}$ solution of purified antibody in $0.1 \mathrm{~m}-\mathrm{NaHCO}_{3}, \mathrm{pH} 8.4$. After reacting at room temperature for $4 \mathrm{~h}$, unconjugated biotin was removed by dialysis overnight against PBS, $0.1 \%$ sodium azide. The optimal ratio of biotin to protein was determined by testing biotinylated antibodies on tissue sections in indirect immunofluorescence using fluoresceinated avidin as the final layer. Rhodamine and fluorescein conjugates were absorbed on bovine liver powder to remove high background staining of epidermis on tissue sections.

Tissue sections were prepared from forelimbs fixed by immersion at $4^{\circ} \mathrm{C}$ for $45 \mathrm{~min}$ in $0.01 \mathrm{M}$ sodium periodate, $0.1 \mathrm{M}$-lysine- $\mathrm{HCl}, 0.05 \%$ paraformaldehyde (McLean \& Nakene, 1974) in HBS followed by a $15 \mathrm{~min}$ wash in HBS. Frozen sections of $10 \mu \mathrm{m}$ were cut from fixed tissue with a cryostat, mounted on coverslips subbed with Gatenby's solution, air-dried, and stored at $-70^{\circ} \mathrm{C}$. In some experiments tissue sections were prepared from mature limbs fixed by freezesubstitution (Gurdon, Partington \& De Robertis, 1974) and embedded in methacrylate as described by Jamrich, Mahon, Gavis \& Gall (1984). One micron sections cut on a glass knife were dried onto subbed slides and stored at room temp. Before staining with antibody, 
methacrylate sections were passed through xylene, $100 \%$ ethanol, and decreasing ethanol concentrations into PBS. This procedure was not suitable when sections were stained with $22 / 18$ since it gave severe loss of antigenicity.

Sections were stained with both $22 / 31$ and $22 / 18$ antibodies by exposing them sequentially to 22/18 (1:200), rabbit-anti-mouse IgM (Mu chain specific, Miles, 1:200), 22/18 (1:200), biotinylated $22 / 31(1: 100)$ and finally rhodamine-conjugated goat-anti-rabbit IgG (Cappel, $1: 100$ ) and fluorescein-conjugated avidin (Vector lab, 1:1000). In this protocol, the sections were reacted a second time with $22 / 18$ in order to saturate any unreacted antigen combining sites on the rabbit-anti-mouse IgM bound in the second layer. Tissue sections were stained with both the $22 / 18$ and 12/101 antibodies by exposing them sequentially to $22 / 18(1: 200)$ and $12 / 101$ (IgG) (1:100), rabbit-anti-mouse IgM (Mu chain specific, Miles, 1:100), and then to rhodamineconjugated goat-anti-rabbit IgG (Cappel, 1:100) and fluorescein-conjugated goat-anti-mouse IgG (gamma chain specific, Cappel, 1:50). The same protocol was used to stain with $22 / 18$ and the myelin Po protein by substituting 12/101 with 30/3, 30/14 and 30/26 (IgG, all diluted 1:100). All layers were incubated for $45 \mathrm{~min}$ at room temp. and followed by three washes with PBS, $0.1 \%$ sodium azide with the exception of incubations using fluoresceinated avidin which were for 10-15 min to reduce background staining. After the last layer, sections were postfixed in acid alcohol (95\% ethanol: $5 \%$ acetic acid), neutralized, counterstained with $0.5 \mu \mathrm{g} \mathrm{ml}^{-1}$ solution of Hoechst 33258 in PBS to detect nuclei, desalted by dipping in distilled water and mounted in $90 \%$ glycerol, $10 \%$ PBS, $2.0 \%, 1,4$ diazabicycol 2.2 .2 octane, $\mathrm{pH} 8.0$. Control experiments in which monoclonal antibodies were omitted or non-specific monoclonal antibodies were substituted gave low-background staining except occasionally on the epidermis.

Sections were viewed and photographed under a Zeiss photomicroscope III equipped with Nomarski optics, epifluorescence and filter systems to separate Hoechst dye, fluorescein, and rhodamine fluorescence. Photographs were taken on Kodak Ektachrome film (ASA 400) with manually determined exposure periods.

\section{Labelling index of $22 / 18^{+}$and $22 / 18^{-}$cells in denervated versus innervated blastemas}

Animals were bilaterally amputated and then denervated on one side by cutting the spinal nerves at the level of the brachial plexus at either 10 days (early bud, four animals) or 20-25 days (late bud-palette, eight animals) after amputation. Two days after denervation, animals were injected intraperitoneally with $25 \mu \mathrm{Ci}\left[{ }^{3} \mathrm{H}\right]$ thymidine (Amersham, $86 \mathrm{Ci} \mathrm{mole}^{-1}$ ) in $0.05 \mathrm{ml}$ HBS. $24 \mathrm{~h}$ after injection of label, the innervated and denervated forelimbs were removed, fixed in periodate-lysine as described above, mounted together in embedding medium and sectioned transversely. Five to eight sections from several different levels of the blastemas were collected onto subbed slides. Sections were stained with $22 / 18$ and with Hoechst dye as described above. For autoradiography, slides were desalted, dried and dipped in liquid emulsion (Ilford, K5 diluted $1: 1$ in water), dried and stored at $4^{\circ} \mathrm{C}$. After 3-4 days, the slides were developed in D19 (Kodak, diluted 1:1 in water) for $3 \mathrm{~min}$, stopped in $20 \%$ acetic acid for $0.5 \mathrm{~min}$, fixed in Hypam fixer (Ilford, diluted 1:4 in water), washed in distilled water for $15 \mathrm{~min}$, and then dried and mounted as above.

\section{RESULTS}

\section{Antibody production}

Table 1 lists the properties of several hybridomas that were obtained from mice immunized with differentiated tissue. Fig. 1 shows examples of staining a mature newt limb with a myofibre antibody, 12/101 (Fig. 1A,B) and with an antibody for myelinating Schwann cells, 30/26 (Fig. 1C,D). In each case, it was relatively easy to obtain markers that were specific for a differentiated cell type since monoclonal 
antibodies derived from mice immunized with differentiated tissue usually included several that appeared to show specific staining. This result probably reflects the high abundance of cell-specific molecules in differentiated tissue. For example, the monoclonal antibodies against myelin $(30 / 3,30 / 14,30 / 26$ in Table 1$)$ were found by Western blotting analysis to be directed against the major myelin glycoprotein, Po, which accounts for over $50 \%$ of the protein in rat peripheral myelin (Wood \& Dawson, 1973; Greenfield, Brostoff \& Hogan, 1980). The Po protein is apparently only produced in significant levels by Schwann cells in association with the myelinated type of axon (Brockes, Fryxell \& Lemke, 1981).

It was more difficult to obtain monoclonal antibodies that served as markers for blastemal cells. In initial experiments, tissue homogenates or a crude membrane fraction were prepared from blastemas of forelimbs at the mid-bud stage of regeneration. Approximately 1000 antibody secreting clones were screened from seven animals immunized with this material. About 250 of these clones stained tissue sections of the regenerating limb but were found either to bind to extracellular matrix components present throughout the limb or to the epidermis, which was the major differentiated tissue in the immunogen. In order to enrich for blastemal antigens, cells were mechanically dissociated from the blastema and partially purified by centrifugation through Ficoll gradients (see Materials and Methods). The hybridomas that arose from animals immunized with this material included two specificities of interest. One specificity, represented by $22 / 31$, was relatively common (four examples). This class of antibody recognized antigens present in connective tissue fibroblasts in mature tissue and some blastemal cells in regenerating limbs. The second specificity, represented by a single clone $22 / 18$, appeared not to stain tissue in the mature limb but stained cells in the blastema.

Table 1. Isolation of monoclonal antibodies as cell markers

\begin{tabular}{lcccc}
\hline Immunogen & $\begin{array}{c}\text { Clones } \\
\text { tested (A) }\end{array}$ & No. specific & $\begin{array}{c}\text { Representative } \\
\text { clones }\end{array}$ & $\begin{array}{c}M_{\mathrm{r}} \text { antigen } \\
\times 10^{3}(\mathrm{~B})\end{array}$ \\
\hline Muscle & 105 & 10 & $12 / 101$ & 120 \\
Myelin & 33 & 6 & $30 / 3$ & $20-25$ \\
& & & $30 / 14$ & \\
Cartilage & 121 & 7 & $30 / 26$ & $\mathrm{ND}$ \\
Total Blastema & 1000 & 0 & $10 / 58$ & - \\
Blastema Cells & 312 & 1 & - & $(\mathrm{C})$ \\
& & 4 & $22 / 18$ & 51
\end{tabular}

(A) The clones that were tested by immunofluorescence on tissue sections had first been scored as positive in an ELISA assay for mouse immunoglobulin (muscle, cartilage, or blastemal immunization) or for myelin (myelin immunization).

(B) Relative molecular masses $\left(M_{\mathrm{r}}\right)$ of antigens recognized on immunoblots of crude homogenates of muscle or blastemal tissue, or purified myelin after their separation in polyacrylamide gels containing sodium dodecyl sulphate and reducing agent as previously described (Fritz \& Brockes, 1983).

(C) Attempts to immunoblot the 22/18 antigen have been unsuccessful thus far. The staining of blastemal cells appears to be cytoplasmic and filamentous. ND: not tested. 
$22 / 31$ and $22 / 18$ were further characterized by staining a series of regenerating limbs at different stages, using several animals at each stage, and their properties are summarized in Table 2 .
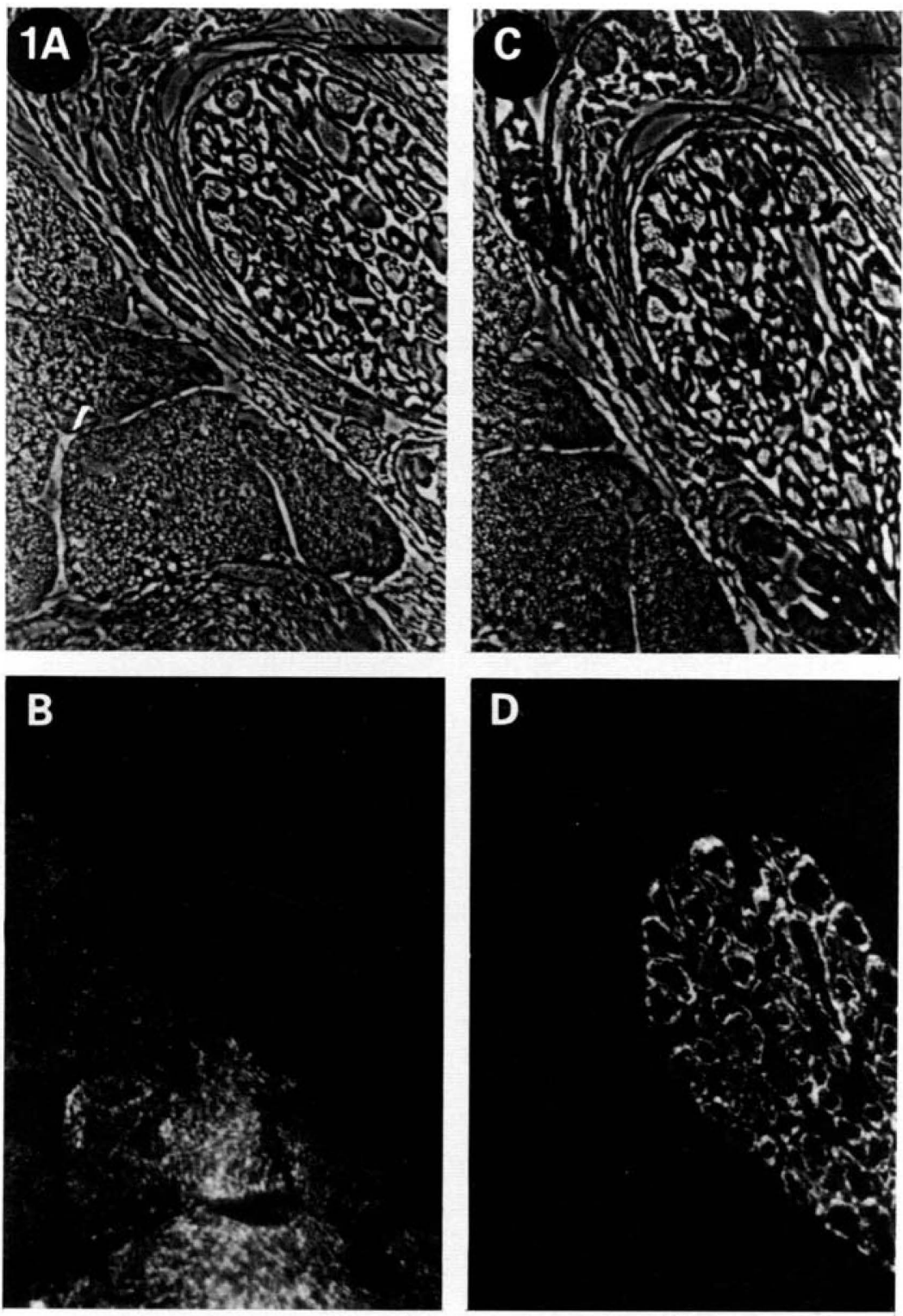

Fig. 1. Staining of the normal limb with myofibre and myelin markers. Methacrylate sections were stained with a myofibre marker, 12/101, and a myelin marker, 30/26, as described in Materials and Methods. (A) A region of the limb containing muscle (left field) and the nerve sheath (right field) viewed under phase-contrast optics (bar = $30 \mu \mathrm{m}$ ) and (B) rhodamine optics to show staining of myofibres with 12/101. (C) Approximately the same region as in A and B on an adjacent section viewed under phase-contrast optics $(\mathrm{bar}=35 \mu \mathrm{m})$ and $(\mathrm{D})$ rhodamine optics to show staining of the myelin sheaths with $30 / 26$. 


\section{Expression of 22/31 and 22/18 in the regenerating limb}

It is important to note the standard conditions that were used for immunofluorescence staining of tissue sections with $22 / 18$ and $22 / 31$. Purified monoclonal antibodies gave optimal staining when used at $5-10 \mu \mathrm{g} \mathrm{ml}^{-1}$. Tissue was routinely fixed before sectioning by immersion in a periodate-lysine fixative. The binding of $22 / 31$ and 22/18 to tissue sections was detected as outlined in Table 2 and described in the Materials and Methods. Three points should be noted about these detection methods. Firstly, the use of three layers rather than two, considerably amplified the fluorescence signal for $22 / 18$. Secondly, since $22 / 18$ is an IgM antibody, it proved more sensitive to use a second antibody raised against IgM rather than one against IgG. Thirdly, 22/31 was conjugated with biotin and detected with fluoresceinated avidin because this method is one way that allows the separate detection of 22/31 and 22/18 (both IgM) on the same section.

Fig. 2 diagrammatically summarizes $22 / 31$ staining in the mature limb and at different stages of regeneration. 22/31 stains fibroblasts of connective tissue present in dermis, muscle, perichrondrium and the nerve sheath in the mature limb (Fig. 2A). After amputation, most cells in the early-bud blastema do not stain with 22/31 (Figs 2C and 3C). The subpopulation of cells that does stain is present at about the same density as in normal tissue and may therefore represent the contribution of connective tissue fibroblasts present before amputation. The area in the early-bud blastema that lies underneath and against the wound epidermis, however, is often a site where additional cells stain brightly with 22/31 (Fig. $3 \mathrm{D}, \mathrm{E})$. As the blastema reaches the late-bud stage, the staining of cells in the blastema with 22/31 changes dramatically (Fig. 2D). Most, if not all, blastemal cells stain with $22 / 31$ (Fig. 4A,C and D,F). This staining is most intense at the blastema tip and decreases proximally. Blastemal cells continue to stain with 22/31 in this manner until differentiation in the blastema begins. As cells differentiate into cartilage, they lose $22 / 31$ staining and chondrocytes express very low or undetectable levels of $22 / 31$. In areas of muscle differentiation, the expression of 22/31 appears to be lost even earlier (see below).

Fig. 2 diagrammatically summarizes $22 / 18$ staining in the mature limb and at different stages of regeneration. 22/18 does not stain cell types in sections of a mature limb with one exception. An intermittent punctate staining is sometimes

Table 2. Properties of 22/18 and 22/31

\begin{tabular}{lllll}
\hline Hybridoma & $\begin{array}{l}\text { Method of } \\
\text { detection }\end{array}$ & Mature limb & Early stage & Later stage \\
\hline $22 / 18$ & $\begin{array}{l}\text { 1st: Rabbit anti- } \\
\text { mouse IgM } \\
\text { 2nd: Rhodamine } \\
\text { goat anti-rab IgG }\end{array}$ & $\begin{array}{l}\text { No detectable } \\
\text { staining }\end{array}$ & $\begin{array}{l}\text { Majority of } \\
\text { blastemal cells }\end{array}$ & $\begin{array}{l}\text { Minority of } \\
\text { blastemal cells }\end{array}$ \\
$\begin{array}{l}\text { FITC-Avidin } \\
\text { (Biotinylated) }\end{array}$ & $\begin{array}{l}\text { Fibroblasts in } \\
\text { connective tissue }\end{array}$ & $\begin{array}{l}\text { Minority of } \\
\text { blastemal cells }\end{array}$ & $\begin{array}{l}\text { Majority of } \\
\text { blastemal cells }\end{array}$ \\
\hline
\end{tabular}




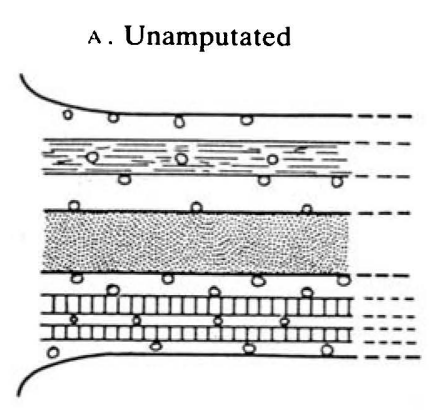

c. Early-mid bud

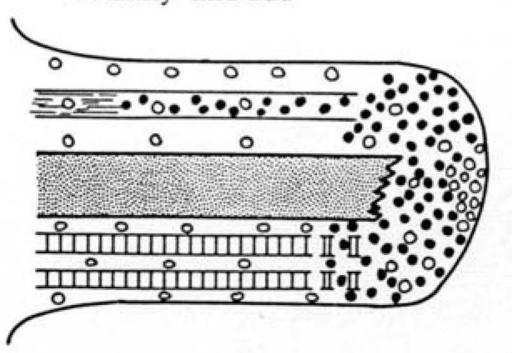

B. Wound healing

Nerve

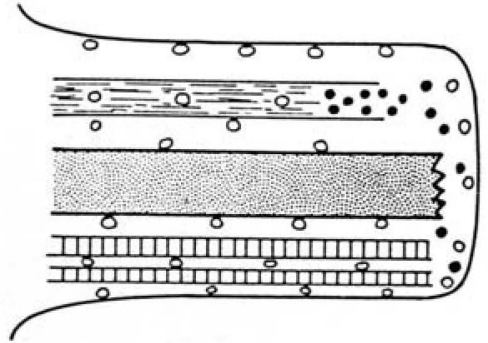

D. Late bud

Nerve

Bone

Muscle

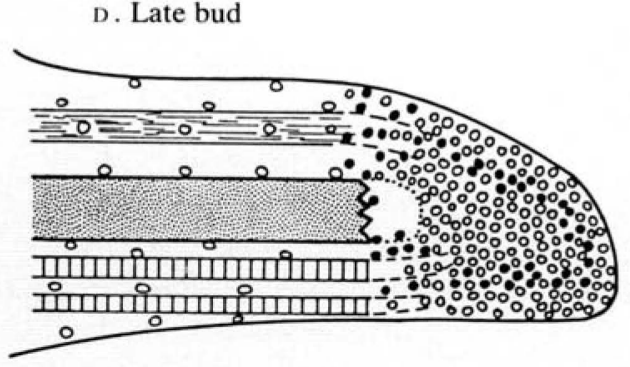

Fig. 2. Schematic diagram of $22 / 18^{+}$and $22 / 31^{+}$cells in the mature and regenerating forelimb. The occurrence of $22 / 18^{+}$cells (closed circles) and $22 / 31^{+}$cells (open circles) in dermis, nerve, bone, muscle and the blastema in (A) an unamputated, mature limb, (B) a regenerating limb at wound healing, (C) a regenerating limb at the early- to medium-bud stage, or (D) a regenerating limb at the late-bud stage.

observed within the nerve but it is not known if this staining is cellular. 22/18 staining first appears at high levels four days after amputation on cells in the nerve sheath and to a lesser extent on scattered cells among muscle (Fig. 2B). As the early blastema forms and breakdown of mature tissue occurs more proximally, most blastemal cells among degenerating muscle, cartilage, and the nerve sheath stain with $22 / 18$, as well as the majority of cells in the blastema itself (Figs $2 \mathrm{C}$, $3 \mathrm{~A}, \mathrm{~B})$. When the blastema grows into a bud, however, the $22 / 18$ staining changes dramatically (Fig. 2D). At the base of the blastema, 22/18 staining is similar to early stages, but in the growing blastema, $22 / 18$ stains only a subpopulation

Fig. 3. 22/31 and 22/18 staining at early-bud stages. Tissue sections of an early-bud, forelimb blastema were stained with both $22 / 18$ and $22 / 31$ as described in Materials and Methods using techniques to separately detect $22 / 18$ binding with rhodamine and $22 / 31$ binding with fluorescein. (A) A field in the middle of the blastema photographed under Nomarski optics, and (B) rhodamine optics to detect $22 / 18$ staining or (C) fluorescein optics to detect $22 / 31$ staining. Note that only a few cells stain with $22 / 31$ while a majority stain with $22 / 18$. Furthermore, the $22 / 31^{+}$cells do not stain, or stain very lightly, with $22 / 18$. (D) A field in the tip of the blastema underneath the wound epidermis photographed with Nomarski optics, or (E) rhodamine optics to detect $22 / 18$ staining or $(F)$ fluorescein optics to detect $22 / 31$ staining. The left side of this field contains epidermis that does not stain with either antibody. Of the blastemal cells in this field, some stain with just $22 / 18$, some with just $22 / 31$ and some with both. Bar $=50 \mu \mathrm{m}$. 
of cells (Fig. 4A,B and C,D). These 22/18 cells are present along the entire length of the blastema, tend to be clustered, and lie between the epidermis and the central core of the blastema. As blastemal cells differentiate into mature tissue, the $22 / 18$ staining is lost.

The staining of regenerating limbs at different stages with $22 / 31$ and $22 / 18$ indicates that $22 / 18^{+}$cells are predominant in the blastema at early stages ( 4 days
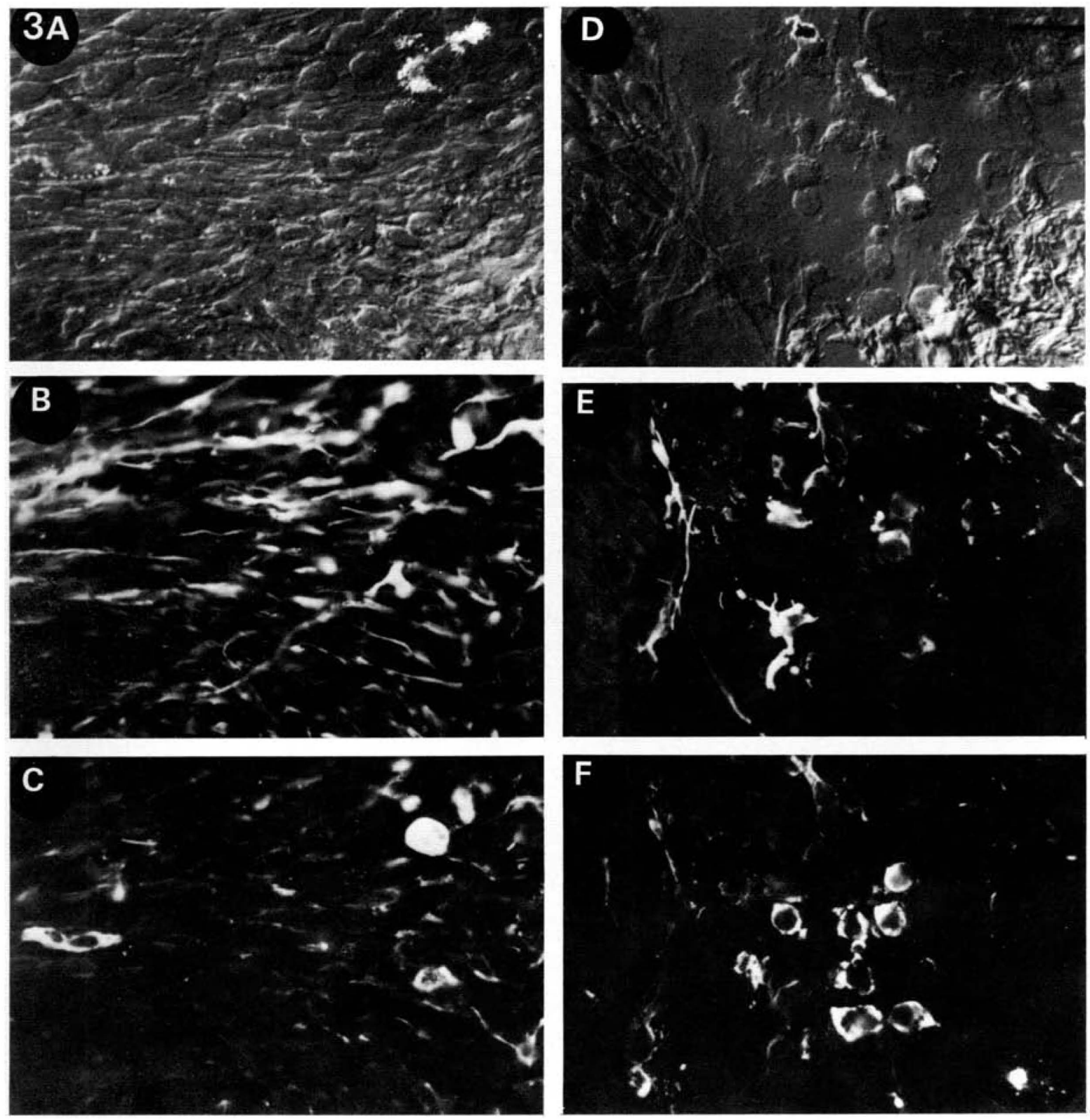

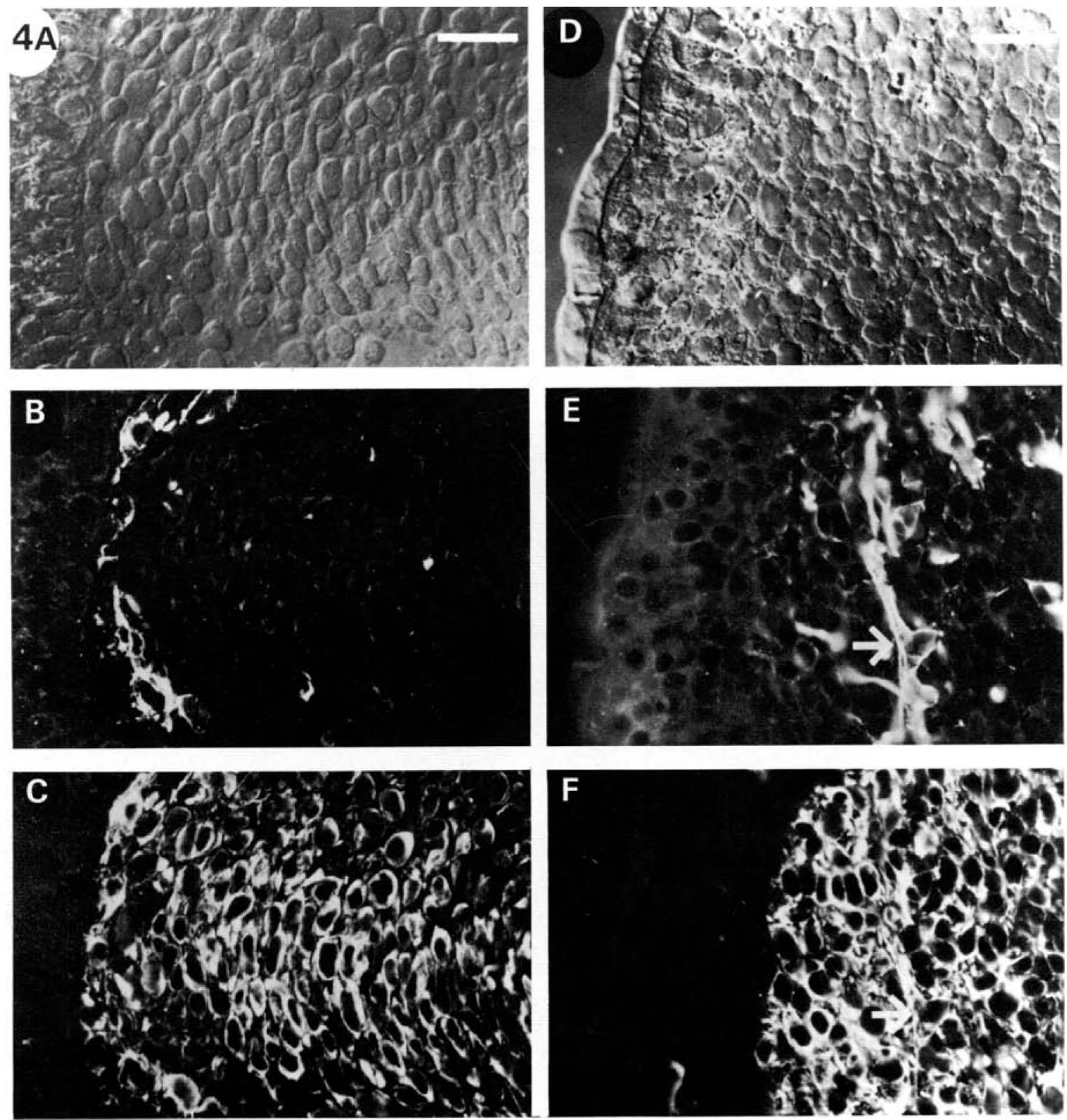

Fig. 4. 22/18 and 22/31 staining at late-bud stage. Longitudinal sections of a late-bud, forelimb blastema were stained with both $22 / 18$ and $22 / 31$ as described in the legend to Fig. 3. (A) A field at the tip of the blastema underneath the wound epidermis photographed with Nomarski optics, or (B) rhodamine optics to detect $22 / 18$ staining or (C) fluorescein optics to detect $22 / 31$ staining. Note that many of the blastemal cells stain with $22 / 31$ while only a subpopulation stains with $22 / 18$. (D),(E) and (F) A field in a tissue section of a different late-bud-stage blastema photographed in the same way as in A,B and C. Note that $22 / 18$ only stains a subpopulation of blastemal cells and these cells (arrow in E) are mainly $22 / 31^{+}$. (Bars $=50 \mu \mathrm{m}$.) 
after amputation until medium bud) while $22 / 31^{+}$cells are predominant at later stages (after medium bud). By staining with double labels, it is possible to estimate the degree of overlap between these two populations. In early stages of regeneration when $22 / 18^{+}$cells are predominant in the blastema, very few of the blastemal cells stain with both $22 / 18$ and $22 / 31$ (Fig. 3A-C). One exception is a population of cells underneath the wound epidermis at the most distal tip of the blastema which tend to stain with both $22 / 31$ and $22 / 18$. At late stages of regeneration when $22 / 31^{+}$cells are predominant, almost all $22 / 18^{+}$cells outside of areas of cytodifferentiation also stain with 22/31 (Fig. 4).

\section{$22 / 18$ staining in the nerve sheath}

$22 / 18$ stains cells in the distal regions of the nerve sheath soon after amputation (Fig. 2B) and this staining of the nerve sheath increases in intensity and occurs more proximally as regeneration proceeds (Fig. 2C). From the appearance of the staining, it seemed likely that the 22/18 antigen is localized in Schwann cells of the nerve sheath after amputation. To examine this possibility, the expression of $22 / 18$ in the nerve sheath was compared with the expression of Po, the major protein of peripheral myelin and a marker associated with Schwann cell differentiation. Tissue sections of early-bud regenerates were stained with both $22 / 18$ and monoclonal antibodies to newt Po (Table 1 and Fig. 1C,D) using a doublelabelling technique. In the most proximal regions of the regenerating limb, the nerve sheath stains intensely with the Po antibodies but not with 22/18. The nerve sheath in more distal regions of the limb stains at low levels with 22/18 in addition to the staining with Po antibodies. The 22/18 and Po staining of the intact nerve sheath is so dense, however, that it is difficult to determine if the antibodies are binding to the same or to separate cells. The nerve sheath is stained with the Po antibodies until the point at which it enters the blastema and breaks apart with the loss of the perineurium. These cells often stain with Po antibodies and, in some cases, also stain with $22 / 18$ (Fig. 5A-C). In the distal regions of the early blastema where most cells stain with $22 / 18$, there is no staining with the Po antibodies. The simplest interpretation of these observations is that Schwann cells express 22/18 when they dedifferentiate and divide but Schwann cells which have migrated from the nerve sheath into the blastema no longer express Po at detectable levels. It should be noted that cells staining for Po and 22/31 were not observed.

\section{$22 / 18$ is associated with myogenesis in late stages of regeneration}

$22 / 18$ stains only a subpopulation of blastemal cells at medium bud and later stages of regeneration. This subpopulation is present along the entire proximal-distal axis of the blastema but tends to be excluded from central regions of the blastema (Fig. 2D). The location of $22 / 18^{+}$cells in the histologically undifferentiated blastema corresponds to prospective areas of myogenesis, raising the possibility that cells expressing $22 / 18$ are destined to form myotubes. To determine if $22 / 18^{-}$cells differentiate into muscle, palette-stage regenerates were 
sectioned and stained with both $22 / 18$ and a marker for myofibres, 12/101 (Table 1, Fig. 1A,B), using a double-labelling technique (Kintner \& Brockes,
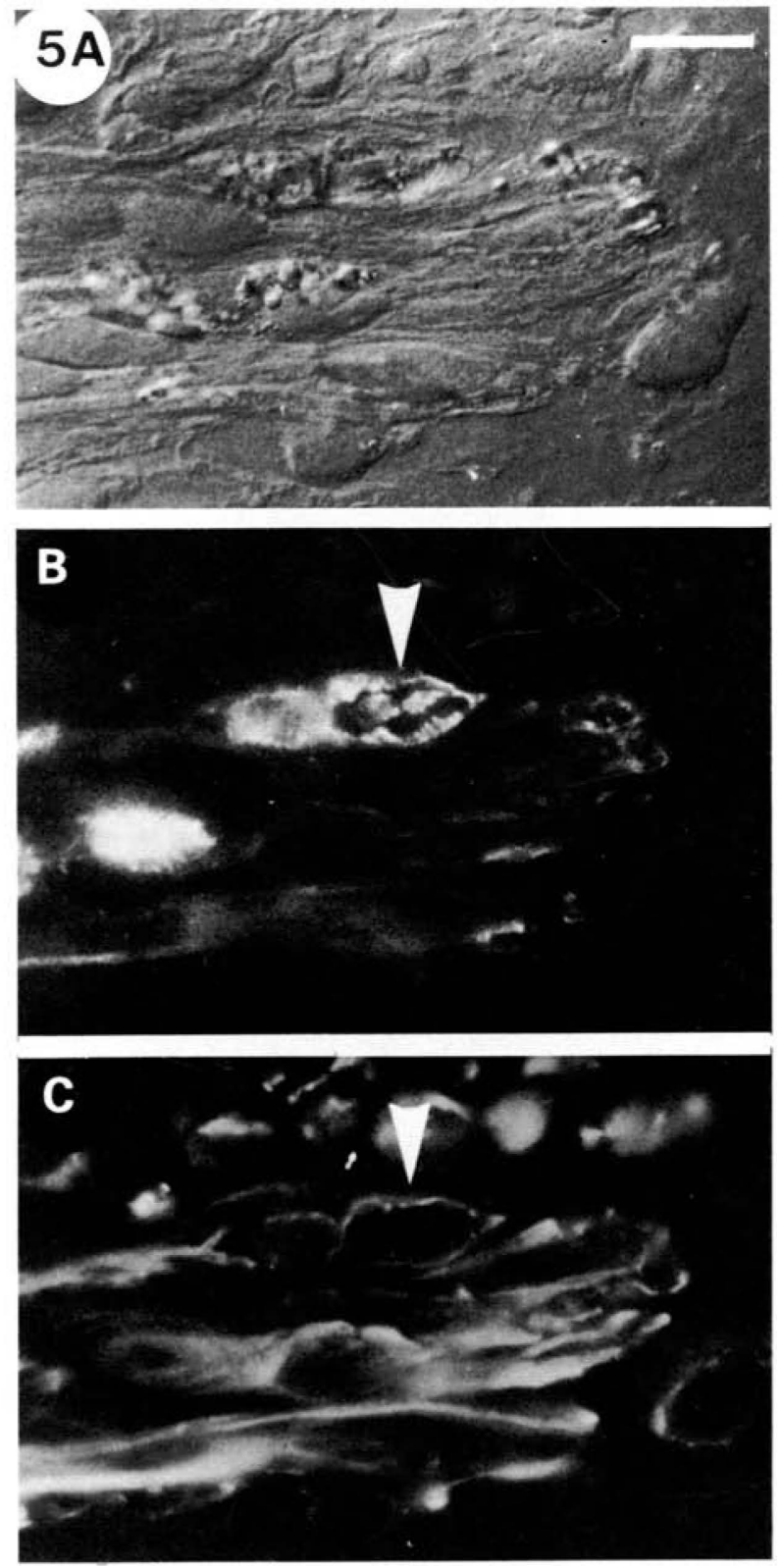

Fig. 5. 22/18 and myelin staining in the early-bud stage. Longitudinal tissue sections of an early-bud, forelimb blastema were stained with both $22 / 18$ and with $30 / 3,30 / 14$ and 30/26. (A) A region of the limb between the blastema and mature tissue was photographed under Nomarski optics (bar $=20 \mu \mathrm{m}$ ), (B) fluorescein optics to detect the Po antibodies or (C) rhodamine optics to detect $22 / 18$ staining. In this photograph, the nerve runs from mature tissue on the left to the blastema on the right. Note the presence of cells that stain with both $22 / 18$ and the Po antibodies. 
1984). The newly-formed myotubes in the proximal regions of the blastema stain with the myofibre marker but not with $22 / 18$ while cells in the distal and histologically undifferentiated regions of the blastema stain with $22 / 18$ but not with $12 / 101$. In regions of the blastema just distal to the newly formed myotubes, there are mononucleated cells that stain with the myofibre marker. Some of these cells also stain with $22 / 18$ indicating that some $22 / 18^{+}$cells differentiate into muscle. Cells which have fused to form myotubes do not appear to express 22/18. In cross section (Fig. 6), it is apparent that the regions staining with $22 / 18$ (Fig. 6B) correlate with regions that differentiate into muscle (Fig. 6C). In many of these regions, it is common to find cells that stain with both 12/101 and 22/18 (Fig. 6E,F).

Sections of palette-stage regenerates were also stained with both $22 / 31$ and the myofibre marker. Mononucleated cells that expressed the myofibre antigen were detected just distal to newly formed myotubes. None of these cells, however, expressed $22 / 31$ even though many $22 / 31^{+}$cells were present in this region and were often adjacent to cells expressing the myofibre antigen.

\section{The effects of denervation on division of $22 / 18^{+}$cells}

Denervation of regenerating limbs eliminates blastemal growth during early stages of regeneration. At about the late-bud stage, however, this growth becomes relatively nerve independent (Singer \& Craven, 1948). The transition of the blastema from a nerve dependent to an independent stage correlates with the change in the proportion of $22 / 18^{+}$cells in the blastema. This correlation is of consequence if cells that differ in $22 / 18$ staining also differ in their dependence on the nerve for division. The relative labelling index of $22 / 18^{+}$and $22 / 18^{-}$cells was determined in the presence and absence of the nerve at early and late stages of regeneration. Animals were bilaterally amputated, and then unilaterally denervated at either 10 days after amputation when the blastemal growth is nerve dependent or at 20-25 days after amputation when it is relatively nerve independent. The labelling index of cells in the blastema was determined 2 days after denervation by injection of $\left[{ }^{3} \mathrm{H}\right]$ thymidine. $24 \mathrm{~h}$ after injection of label, forelimbs were fixed and processed for 22/18 staining and autoradiography as described in Materials and Methods. The labelling indices were calculated by counting the number of $22 / 18^{+}$and $22 / 18^{-}$cells with labelled nuclei as well as total nuclei in four random fields from four different sections for each limb (1000 total nuclei/ limb). For each animal, the labelling indices of $22 / 18^{+}$and $22 / 18^{-}$cells for the limb on the denervated side were divided by indices on the innervated side to give ratios which reflect the effect of denervation on division of $22 / 18^{+}$and $22 / 18^{-}$ cells. The data are expressed in Table 3 as a mean \pm standard error of this ratio determined for four animals at an early time and eight animals at a late time. The percentage of labelled nuclei that stained with $22 / 18$ was $75 \pm 9 \%$ at early times and $27 \pm 4 \%$ at late times. The results in Table 3 indicate that the labelling index of $22 / 18^{+}$cells drops seven-fold upon denervation at either early or late stages while the labelling of $22 / 18^{-}$cells drops three-fold at early times and only $1 \cdot 4$-fold at late stages. It is apparent that $22 / 18^{+}$cells remain nerve dependent for division 

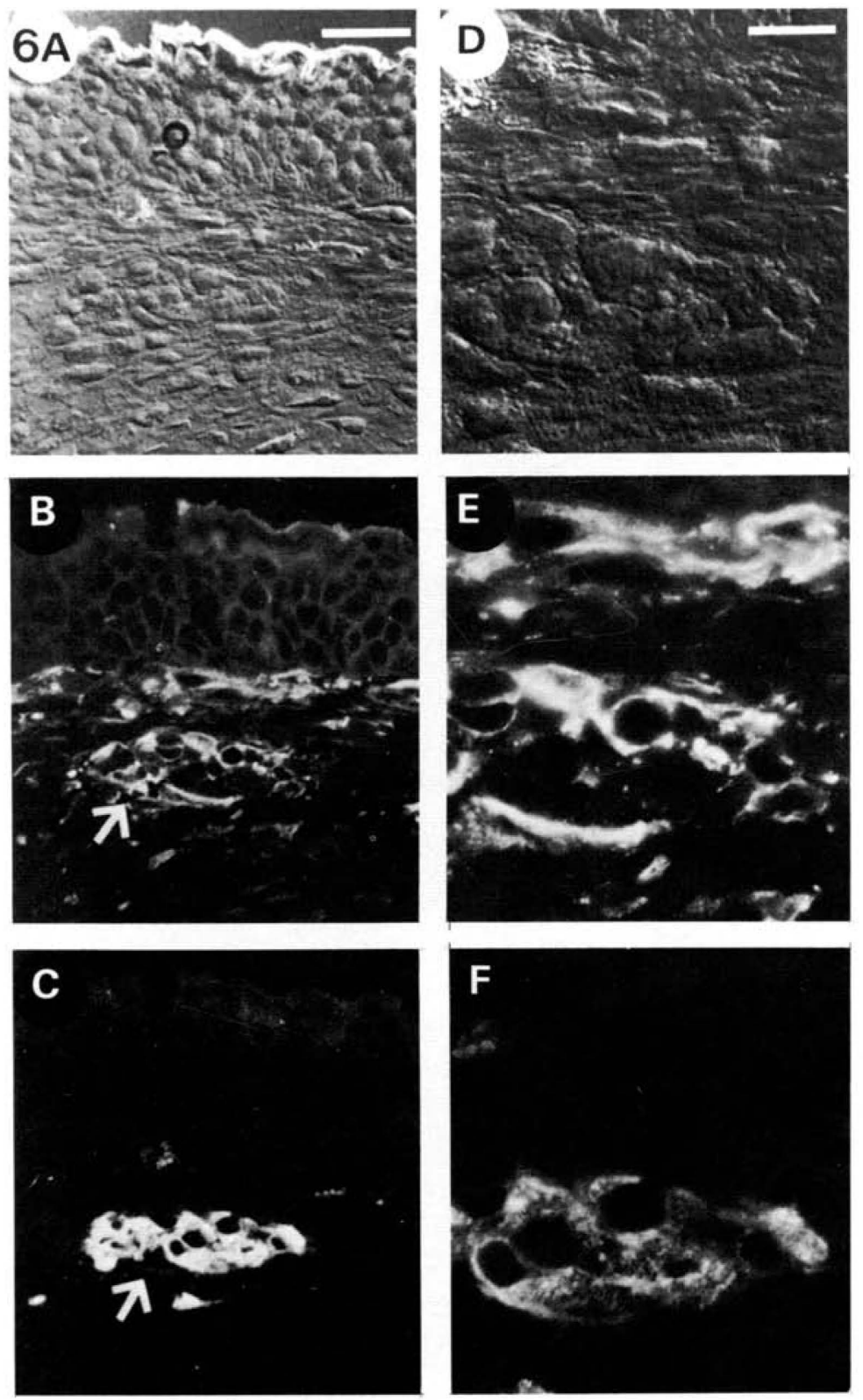

Fig. 6. 22/18 and myofibre staining in the palette-stage regenerate. Transverse tissue sections of a palette-stage regenerate were stained with both $22 / 18$ and $12 / 101$ as described in Materials and Methods. (A) A section of the regenerate containing a region of muscle differentiation was photographed under Nomarski optics (bar = $50 \mu \mathrm{m}$ ) with epidermis in the upper field and newly formed cartilage in the lower field. (B) Same region photographed with rhodamine optics to detect $22 / 18$ staining and (C) fluorescein optics to detect $12 / 101$ staining. Note that an area where 22/18 staining occurs is a site of $12 / 101$ staining (large arrow). (D,E and F) are photographed under the same conditions but at a higher magnification (bar $=20 \mu \mathrm{m})$. 
at late stages of regeneration while the $22 / 18^{-}$cells may become progressively nerve independent.

\section{DISCUSSION}

\section{Derivation of cell markers}

It has been relatively straightforward to obtain marker antibodies for myofibres, Schwann cells and cartilage, presumably because these differentiated cells express specific molecules at high levels as exemplified by the Po glycoprotein of peripheral myelin. In contrast, it has been difficult to obtain antibodies that react with the undifferentiated blastemal cells but not with mature tissue. The 22/18 reagent was obtained only after screening about 1300 antibody-secreting clones (Table 1). It is probable that molecules characteristic of progenitor cells are present at lower levels than those that mark differentiated cells. In order to focus the immune response on progenitor cell antigens, it is therefore necessary to purify the cells away from extracellular matrix and differentiated cells. The regeneration blastema is one of the few examples in vertebrates where progenitor cells can be readily isolated in sufficient numbers to use as immunogen.

\section{The 22/18 cell marker}

The distribution of the 22/18 antigen in the limb at early stages of regeneration is quite striking, and invites some speculations about its significance. The antigen is not detectable in high levels in the normal limb, but appears locally in certain cell types that are in the process of dedifferentiation and is present in most of the blastemal cells during early stages of regeneration. It is not simply a marker for dividing cells, since quiescent cells in the blastema continue to express it (Table 3 and unpublished observations), and dividing cells in other locations, such as the basal layer of the dermis, do not. It is not a universal marker for blastemal cells, even at earlier stages, as evidenced by the pattern of reactivity with the $22 / 31$ reagent that is discussed below. The time and location of $22 / 18$ expression suggest rather that it identifies the appearance of a certain class of blastemal cell. It is important to note, however, than when forelimbs are denervated at the brachial plexus but not amputated, the antigen is expressed by the dedifferentiating

Table 3. The labelling index of $22 / 18^{+}$and $22 / 18^{-}$cells in the denervated versus innervated blastema

\begin{tabular}{lccc}
\hline \multirow{2}{*}{$\begin{array}{l}\text { Stage and time of } \\
\text { denervation }\end{array}$} & \multicolumn{3}{c}{$\begin{array}{c}\text { Ratio of labelling indices in } \\
\text { blastema (denervated/innervated) }\end{array}$} \\
\cline { 2 - 4 } $\begin{array}{l}\text { Early bud, } 10 \text { days } \\
(\mathrm{n}=4 \text { newts) }\end{array}$ & $0 \cdot 20 \pm 0.03$ & $0 \cdot 13 \pm 0.02$ & $0.35 \pm \cdot 06$ \\
$\begin{array}{l}\text { Palette, } 25-30 \text { days } \\
(\mathrm{n}=8 \text { newts) }\end{array}$ & $0.52 \pm 0.15$ & $0.14 \pm 0.03$ & $0.77 \pm 0.21$ \\
\multicolumn{2}{c}{ Details of this experiment are given in the Materials and Methods section and the text. } \\
\hline
\end{tabular}


Schwann cells during Wallerian degeneration. This is another context where cells revert from a differentiated state and are mobilized to divide (Bradley \& Asbury, 1970).

Since 22/18 appears to be expressed when blastemal cells arise, it can be used to determine which cell types contribute to the blastema. In previous work (Kintner \& Brockes, 1984), it was shown that $22 / 18$ could be co-localized with a marker for myofibres on a small population of mononucleated cells in early stages of regeneration, and the properties of these cells supported the hypothesis that myofibres give rise to blastemal cells. In a similar approach, it is possible to detect cells in the nerve sheath that stain with both $22 / 18$ and antibodies to Po, and it is likely therefore that Schwann cells give rise to blastemal cells. Schwann cells have been considered in several anatomical studies to contribute to the blastema (Guyenot \& Schotte, 1926; Thornton, 1938; Trampusch \& Harrebomee, 1965) and also in certain experimental cases where nerves appear to support regeneration of an irradiated blastema (Wallace, 1972; Maden, 1977). Thus, the use of 22/18 along with markers for differentiated cells supports the anatomical studies which have concluded that the blastema is derived from several cell types in the limb (Thornton, 1938; Chalkley, 1954), and are contrary to the notion that connective tissue fibroblasts or undifferentiated progenitor cells are the exclusive source. The weakness of the present approach is that markers such as 12/101 or Po are probably lost quite rapidly on dedifferentiation (see Brockes, Fryxell \& Lemke, 1981), and hence it is not possible to determine how many blastemal cells are derived from a particular source.

At later stages of regeneration, 22/18 marks a minority of the blastemal cells and the question arises as to their fate. It is possible that some of these cells may undergo myogenesis since their location in the blastema is characteristic of areas where this occurs (Iten \& Bryant, 1973). More direct evidence for this possibility comes from the detection of cells that stain with both $22 / 18$ and the myofibre marker $12 / 101$. The possibility that $22 / 18$ is an early marker for the myogenic lineage is interesting but requires further investigation. In view of the early contribution of the Schwann cells to the 22/18 population, it is appropriate to ask if some of these cells may later differentiate into Schwann cells. It is not known whether Schwann cells in regeneration arise from blastemal cells or if they migrate from the nerve sheath on ingrowth of the nerve. In either case, some of the $22 / 18^{+}$ cells at later stages could be cells that will enwrap the nerve axons and synthesize myelin. As in the case of the myogenic possibility, more discriminating markers and further studies are required to investigate this hypothesis.

In summary, there is clearly no simple interpretation for the presence of the $22 / 18$ antigen. In the early stages, our previous studies and the present paper show that the antigen is clearly associated with dedifferentiation and the transition from muscle or Schwann cell to blastemal cell. In this sense it is perhaps more a marker of cell 'state' than of a particular blastemal cell type or lineage. In the later stages, by contrast, the restriction of the antigen to blastemal cells in a particular and suggestive location is more indicative of a marker of lineage. At both times, 
nonetheless, it identifies cells whose proliferation is dependent on the nerve. Despite these uncertainties, the antigen has provided new information about blastemal cells and further studies of its significance are warranted.

\section{$22 / 31$ and the changing composition of the blastema}

In the normal limb, antibody $22 / 31$ stains fibroblasts in the dermis, as well as in muscle and nerve. It is appropriate to ask if the $22 / 31$ population in the blastema at different stages is derived wholly or in part from division of the 'resident' population present in the dermis around the blastema, or in muscle and nerve, but we have no rigorous information to answer this important question. Thus 22/31 was not expressed in conjunction with either of the markers (Po or 12/101) for differential cells. A number of investigators have stressed the importance of the dermal contribution for patterning in the blastema (Carlson, 1974; Bryant, 1978; Settles, 1978; Slack, 1980; Tank, 1981), and the 22/31 cells present in this location are clearly deserving of further study.

The pattern of staining with $22 / 18$ and $22 / 31$ indicates that the cellular composition of the blastema changes during regeneration. During early stages, $22 / 18$ stains a majority of cells while $22 / 31$ stains a minority and the two populations do not overlap. At later stages, but before the onset of significant cytodifferentiation in the blastema, the proportions are reversed and doublelabelled cells are present. The importance of this change in cellular composition was examined for the issue of nerve-dependent growth, since it has been shown that denervation has a profound effect on growth at early stages, and much less effect at later stages (Singer \& Craven, 1948). The results (Table 3) indicate that the division of $22 / 18^{+}$cells is nerve dependent at both stages while the division of $22 / 18^{-}$cells is much less so. Since the proportion of $22 / 18^{+}$cells is less at later stages, the change in cell composition is part of the explanation for the different consequences of denervation. It is of interest that $22 / 18$ identifies a population that retains dependence on the nerve for division even at late stages when tissue pattern emerges and indeed retains an identical quantitative dependence to that shown at earlier stages. This insight would be very difficult to obtain without cell markers. One prediction of these considerations (Brockes, 1984) is that the regenerate would be nerve independent for growth if $22 / 18^{+}$cells were replaced with $22 / 18^{-}$cells at earlier stages. This situation may exist in aneurogenic limbs (Yntema, 1959) and could therefore be the basis of nerve-independent regeneration - a possibility that can be readily tested with the available antibodies.

We would like to thank Sarah Joslin for excellent technical assistance and Drs Donna Fekete, Herman Gordon, Nigel Holder and Russel Fernald for critical reading of the manuscript. C.K. was supported by a NRSA fellowship from the National Institute of Health.

\section{REFERENCES}

Bradley, W. G. \& AsBury, A. (1970). Duration of synthesis phase in neurolemma cells in mouse sciatic nerve during degeneration. Expl Neurol. 26, 275-282. 
Brockes, J. P., Fryxell, K. J. \& Lemke, G. E. (1981). Studies on cultured Schwann cells - the induction of myelin synthesis and the control of their proliferation by a new growth factor. J. exp. Biol. 95, 215-230.

Brockes, J. P. (1984). Mitogenic growth factors and nerve dependence of limb regeneration. Science 225, 1280-1287.

Bryant, S. V. (1978). Pattern regulation and cell commitment in amphibian limbs. In The Clonal Basis of Development (ed. S. Subtelmy \& I. M. Sussex), pp. 63-82. New York: Academic Press.

CARLSON, B. M. (1974). Morphogenetic interactions between rotated skin cuffs and underlying stump tissues in regenerating axolotl forelimbs. Devl Biol. 39, 263-285.

CHALKLEY, D. T. (1954). A quantitative histological analysis of forelimb regeneration in Triturus viridescens. J. Morph. 94, 21-70.

EngVall, E. \& Perlman, P. (1972). Enzyme-linked immunosorbent assay, ELISA. J. Immunol. 109, 129-135.

French, V. P., Bryant, P. \& Bryant, S. V. (1976). Pattern regulation in epimorphic fields. Science 913, 969-981.

FrITZ, L. C. \& BRocKEs, J. P. (1983). Immunochemical properties and cytochemical localization of the voltage-sensitive sodium channel from the electroplax of the eel (Electrophorus electricus). J. Neurosci. 3, 2300-2309.

FryXell, K. J., BALzer, D. R. \& Brockes, J. P. (1983). Development and application of a solidphase radioimmunoassay for the Po Protein of peripheral myelin. J. Neurochem. 40, 538-546.

GERAUDINE, J. \& Singer, M. (1981). Scanning electron microscopy of the normal and denervated limb regenerate in the newt, Notophthalmus, including observations on embryonic amphibian limb-bud mesenchyme and blastema of fish-fin regenerate. Amer. J. Anat. 162, 73-87.

Greenfield, S., BrostofF, S. W. \& Hogan, E. L. (1980). Characterization of the basic proteins from rodent peripheral nervous system myelin. J. Neurochem. 34, 453-455.

Gurdon, J. B., Partington, G. A. \& De Robertis, E. M. (1974). Injected nuclei in frog oocytes: RNA synthesis and protein exchange. J. Embryol. exp. Morph. 36, 541-553.

GuYENot, E. \& SchotTe, O. E. (1926). Demonstration de l'existance de territories specifique de regeneration par la methode de la deviation des troncs nerveux. C. r. Séanc Soc. Biol. 194, 1050-1052.

HAY, E. D. (1962). Cytological studies of dedifferentiation and differentiation in regenerating amphibian limbs. In Regeneration (ed. D. Rudnick), pp. 177-210. New York: Ronald Press.

ITEN, L. E. \& BRYANT, S. V. (1973). Forelimb regeneration from different levels of amputation in the newt, Notophthalmus viridescens: length, rate and stages. Wilhelm Roux' Arch. EntwMech. Org. 173, 263-282.

Jamrich, M., Mahon, K. A., Gavis, E. R. \& Gall, J. G. (1984). Histone RNA in amphibian oocytes visualized by in situ hybridization to methacrylate embedded tissue sections. EMBO J. 3, 1939-1943.

KinTNER, C. R. \& Brockes, J. P. (1984). Monoclonal antibodies identify blastemal cells derived from de-differentiating muscle in limb regeneration. Nature 308, 67-69.

KöHLER, G. \& MilsteIn, C. (1975). Continuous cultures of fused cells secreting antibody of predefined specificity. Nature 256, 495-497.

Maden, M. (1977). The role of Schwann cells in paradoxical regeneration in the axolotl. J. Embryol. exp. Morph. 41, 1-13.

Mclean, I. N. \& NaKane, P. K. (1974). Periodate-lysine paraformaldehyde fixative. A new fixative for immunoelectron microscopy. J. Histochem. Cytochem. 22, 1077.

Mishell, B. B. \& SHIIGI, S. M. (1980). Selected Methods in Cellular Immunology. San Francisco: W. H. Freeman and Comp.

Moore, H.-P. H., Fritz, L. C., Raftery, M. A. \& Brockes, J. P. (1982). Isolation and characterization of a monoclonal antibody against the saxitoxin-binding component from the electric eel Electrophorus electricus. Proc. natn. Acad. Sci., U.S.A. 79, 307-310.

SAlPETER, M. M. \& Singer, M. (1960). The fine structure of mesenchymatous cells in the regenerating forelimb of the adult newt, Triturus. Devl Biol. 2, 516-534.

SETTLES, H. E. (1978). Morphogenetic effects of limb skin during limb regeneration in the adult newt, Triturus viridescens. Anat. Rec. 166, 375. 
Singer, M. \& CRAVEN, L. (1948). The growth and morphogenesis of the regenerating forelimb of adult Triturus following denervation at various stages of development. J. exp. Zool. 108, 279-308.

SLACK, J. M. W. (1980). Morphogenetic properties of the skin in axolotl limb regeneration. J. Embryol. exp. Morph. 58, 265-288.

TANK, P. W. (1981). The ability of localized explants of whole or minced dermis to disrupt pattern formation in the regenerating forelimb of the axolotl. Am. J. Anat. 162, 315-326.

ThorNTon, C. S. (1938). The histogenesis of muscle in the regenerating forelimb of larval Ambystoma punctatum. J. Morph. 62, 17-47.

THORNTON, C. S. (1942). Studies on the origin of the regenerating blastema in Triturus viridescens. J. exp. Zool. 89, 375-390.

Trampusch, H. A. L. \& Harrebomee, A. E. (1965). In Regeneration in Animals and Related Problems (ed. V. Kiortsis \& H. A. L. Trampusch). Amsterdam: North-Holland.

WALLACE, H. (1972). The components of regrowing nerves which support the regeneration of salamander limbs. J. Embryol. exp. Morph. 28, 419-435.

Wallace, H. (1981). Vertebrate Limb Regeneration. Chichester: John Wiley.

Wood, J. G. \& Dawson, R. M. (1973). A major myelin glycoprotein of sciatic nerve. J. Neurochem. 21, 717-719.

YNTEMA, C. L. (1959). Regeneration in sparsely innervated and aneurogenic forelimbs of Ambystoma larvae. J. exp. Zool. 140, 101-123.

(Accepted 26 April 1985) 
